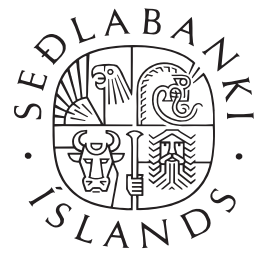

CENTRAL BANK OF ICELAND

WORKING PAPERS No. 12

\title{
THE REPRESENTATIVE HOUSEHOLD'S DEMAND FOR MONEY IN A COINTEGRATED VAR MODEL
}

by

Thórarinn G. Pétursson

January 2001

CENTRAL BANK OF ICELAND

Economics Department 
Central Bank of Iceland Working Papers are published by the Economics Department of the Central Bank of Iceland. The views expressed in them are those of their authors and not necessarily the views of the Central Bank of Iceland.

Also available on the Central Bank of Iceland World Wide Web site (http://www.sedlabanki.is)

All rights reserved. May be reproduced or translated provided the source is stated.

ISSN: 1028-9445 


\title{
The representative household's demand for money in a cointegrated VAR model
}

\author{
THÓRARINN G. PÉTURSSON \\ Central Bank of Iceland, Economics Department, \\ Kalkofnsvegur 1, 150 Reykjavík, Iceland, \\ and \\ Reykjavík University, Ofanleiti 2, 103 Reykjavík, Iceland. \\ E-mail: thorarinn.petursson@sedlabanki.is
}

Received: October 2000

\begin{abstract}
Summary A representative household model with liquidity services directly in the utility function is used to derive a stable, data congruent error correction model of broad money demand in Iceland. This model gives a linear, long-run relation between real money balances, output and the opportunity cost of holding money that is used to over-identify the cointegrating space. The over-identifying restrictions suggest that the representative household is equally averse to variations in consumption and real money holdings. Finally, a forward-looking interpretation of the short-run dynamics, assuming quadratic adjustment costs, cannot be rejected by the data.
\end{abstract}

Keywords: Money demand, Money-in-the-utility function, Cointegration, Forward looking behaviour.

\section{INTRODUCTION}

The modelling of the demand for money has been a major focus of interest in macroeconometrics since the early 1970s. This is not surprising considering its importance for monetary policy and its role in modern economies. The existence of a stable demand function, the link between money and prices, and the endogeneity or exogeneity of money are all recurring issues in the literature. Obtaining stable empirical money demand equations has, however, proven elusive, leading many prominent economists to declare that no such constant relation exists (cf. Goldfeld and Sichel (1990)). Recently, however, a number of empirical studies of money demand have been successful in finding stable money demand relations. Among them are Baba et al. (1991) for the US, Hendry and Ericsson (1991) for the UK and Hoffman et al. (1995) for the US, Japan, Canada, the UK, and West Germany.

The purpose of this paper is to analyse the demand for broad money (M3) in Iceland using annual data for the period between 1962 and 1995. A simple money demand relation is derived from an optimization problem of a representative household with liquidity services directly in 
the utility function. The use of an explicit optimizing model in the cointegrating analysis should facilitate economic interpretation of the long-run parameters of the money demand equation. ${ }^{1}$

The dynamic adjustment towards the long-run equilibrium is approximated in two ways. First, following the general-to-specific approach, the short-run dynamics are estimated freely. ${ }^{2}$ Second, since these dynamics should, in principle, be derived explicitly from optimizing behaviour, the short-run dynamics are estimated assuming quadratic adjustment costs. This gives a forward-looking, rational expectations interpretation of the short-run dynamics of money demand.

The remainder of this paper is organized as follows. Section 2 describes the underlying theoretical model of money demand. Section 3 describes the data and necessary transformations due to financial innovations in the domestic financial system in the last decade. The fourth section presents the estimation results and the final section concludes.

\section{THEORETICAL SPECIFICATION}

\subsection{Money holdings when households face no adjustment costs}

To model households' demand for money it is assumed that money provides direct utility from liquidity services using a standard money-in-the-utility function (MIUF) model. This model allows the utility function to capture the liquidity services of money and has the advantage of being easily tractable and giving log-linear long-run solutions, therefore being easily estimable. Furthermore, Feenstra (1986) has shown that models which explicitly model the transaction services of money can be approximated as MIUF models. This is important since existing models which explicitly model the transaction services of money, such as cash-in-advance models, quickly become cumbersome and often analytically intractable. ${ }^{3}$

The representative household is assumed to solve a two-stage decision process. First the desired path of real money balances is determined and then an independent decision is made concerning the speed of adjustment towards this path. Ideally, one would like a theory that deals with the simultaneous determination of the desired path of money balances and the speed of adjustment. However, such a model would quickly become empirically intractable. It is therefore standard procedure in this literature to treat these problems separately.

Hence, for determining the desired path of real money balances, the representative household is assumed to solve the following infinite horizon problem

$$
\max E_{t}\left[\sum_{i=0}^{\infty} \delta^{i}\left\{u\left(C_{t+i}\right)+\xi v\left(\frac{M_{t+i}}{P_{t+i}}\right)\right\}\right],
$$

\footnotetext{
${ }^{1}$ This approach has two important advantages (cf. Pesaran (1997)). First, it ensures that the model embodies theory-consistent steady-state relations from the outset. Second, to the extent that the theory implies over-identifying restrictions on the long-run relations, it allows the model's long-run properties to be evaluated empirically.

${ }^{2}$ Among earlier studies of money demand in Iceland are Eggertsson (1982), Cornelius (1990) and Gudmundsson (1986). The first two use a partial adjustment framework, whereas the last one uses a conditional error correction model. The demand equations in the first two papers break down in 1979, whereas Gudmundsson, by allowing a richer set of explanatory variables and more flexible dynamics inherent in the error correction approach, finds no such problems. This suggests a potential benefit of estimating the short-run dynamics unrestrictedly.

${ }^{3}$ See Ripatti (1996) and Poterba and Rotemberg (1987) for empirical applications of MIUF models and Lucas (1988) for an empirical application of a cash-in-advance model.
} 
where $C_{t}$ is real-valued consumption and $u(\cdot)$ and $v(\cdot)$ are twice differentiable concave instantaneous utility functions. $E_{t}$ denotes expectations conditional on information at time $t, \delta$ is the discount factor and $\xi$ measures the relative weight of consumption goods and real money balances in the overall utility function.

The representative household allocates its real income, $I_{t}$, along with accrued capital earnings among consumption goods $C_{t}$, bonds $B_{t}$, and real money balances $\frac{M_{t}}{P_{t}}$, where $P_{t}$ is the price of consumption at time $t$ and $B_{t}$ denotes the real value of bonds denominated in unit of time $t$ consumption. These bonds pay a gross real return of $\left(1+r_{t}\right)$ from time $t$ to $t+1$. Real money balances pay the real gross return $\left(1+d_{t}\right) \frac{P_{t}}{P_{t+1}}$, where $\left(1+d_{t}\right)$ is the gross own rate of money from time $t$ to $t+1$. The households budget constraint is then

$$
C_{t}+B_{t}+\frac{M_{t}}{P_{t}} \leq I_{t}+\left(1+d_{t-1}\right) \frac{M_{t-1}}{P_{t}}+\left(1+r_{t-1}\right) B_{t-1} .
$$

The first-order conditions with respect to bond and money holdings are given by the standard Euler conditions

$$
\begin{gathered}
\delta E_{t}\left\{\frac{u^{\prime}\left(C_{t+1}\right)}{u^{\prime}\left(C_{t}\right)}\right\}=\frac{1}{1+r_{t}}, \\
\left(1+d_{t}\right) \delta E_{t}\left\{\frac{P_{t}}{P_{t+1}} \frac{u^{\prime}\left(C_{t+1}\right)}{u^{\prime}\left(C_{t}\right)}\right\}+\xi \frac{v^{\prime}\left(\frac{M_{t}}{P_{t}}\right)}{u^{\prime}\left(C_{t}\right)}=1 .
\end{gathered}
$$

The first Euler equation states that along an optimal path the representative household cannot increase its expected utility by forgoing one unit of consumption in period $t$, investing its value in bonds, and consuming its proceedings at time $t+1$. The second Euler equation states that expected utility cannot be increased by holding one unit less of money at time $t$, investing it in bonds, and consuming its proceedings at time $t+1$.

To solve this model assume that the instantaneous utility functions can be parametrized within the standard constant relative risk aversion (CRRA) class

$$
\begin{aligned}
u\left(C_{t}\right) & =\frac{C_{t}^{1-\omega}}{1-\omega}, \\
v\left(\frac{M_{t}}{P_{t}}\right) & =\frac{\left(\frac{M_{t}}{P_{t}}\right)^{1-\psi}}{1-\psi},
\end{aligned}
$$

where $\omega=\frac{-C u^{\prime \prime}}{u^{\prime}}$ and $\psi=\frac{-\frac{M}{P} v^{\prime \prime}}{v^{\prime}}$ are the constant relative risk aversion coefficients.

Furthermore, assume that $P_{t+1} / P_{t}$ and $C_{t+1} / C_{t}$ are jointly conditionally log-normally distributed. ${ }^{4}$ Taking logs of (2.3), log-linearizing (2.4), and combining gives

$$
\psi(m-p)_{t}=\log \xi+\omega c_{t}+\log \left(1+d_{t}\right)-\log \left(1+r_{t}\right)-E_{t} \Delta p_{t+1}+\sigma_{p t}^{2} / 2-\omega \sigma_{c p t},
$$

where lower case letters denote logs, $\Delta p_{t+1}=p_{t+1}-p_{t}, \sigma_{p t}^{2}=\operatorname{var}_{t} \Delta p_{t+1}$ and $\sigma_{c p t}=$ $\operatorname{cov}_{t}\left(\Delta p_{t+1}, \Delta c_{t+1}\right)$.

\footnotetext{
${ }^{4}$ Unlike the assumption of unconditional log-normality, the assumption of conditional log-normality is not very restrictive. The first two moments of the distribution do not need to be constant but may be time and state dependent. The increments of the log of the variables need not be independent but may be serially correlated.
} 
Finally, assume that the Fisher parity holds

$$
\left(1+i_{t}\right)=\left(1+r_{t}\right) \frac{E_{t} P_{t+1}}{P_{t}},
$$

where $i_{t}$ is the nominal bond rate. Taking logs and substituting into (2.7) gives

$$
\psi\left(m_{t}-p_{t}\right)=\log \xi+\sigma_{p t}^{2}-\omega \sigma_{c p t}+\omega c_{t}-R_{t},
$$

where $R_{t}=\log \left(\frac{1+i_{t}}{1+d_{t}}\right)$ is the interest rate spread.

Assuming that the variance terms are constant through time, a familiar formulation for the long-run money demand relation is obtained ${ }^{5}$

$$
(m-p)_{t}=\kappa+\eta c_{t}-\theta R_{t},
$$

where $\kappa=\left\{\theta\left(\log \xi+\sigma_{p}^{2}\right)-\eta \sigma_{c p}\right\}, \eta=\frac{\omega}{\psi}$ and $\theta=\frac{1}{\psi}$.

This is a standard functional form used in empirical studies on money demand. However, it is more common to use some measure of aggregate income as the scale variable rather than private consumption. This is also done here as the study uses a broad measure of money that not only includes the money holdings of households but also of the corporate sector. Hence, the use of a more broad expenditure variable than private consumption seems appropriate. The steady-state money demand relation analysed in this paper is therefore the following

$$
\left(m^{*}-p\right)_{t}=\kappa+\eta y_{t}-\theta R_{t},
$$

where $y_{t}$ is aggregate income.

Theory is not unified on the size of the long-run income elasticity, $\eta$. In the transaction model of Baumol (1952) and Tobin (1956) $\eta$ equals $\frac{1}{2}$, whereas in the precautionary model of Miller and Orr (1966) it equals $\frac{1}{3}$. The quantity theory of Friedman (1956) predicts, however, a value of unity. The size of $\eta$ is therefore left open as an empirical question. A unit scale elasticity further implies in this model that $\omega=\psi$, i.e. that households are equally risk averse to variations in consumption and real money balances.

\subsection{Dynamic adjustment}

The previous section led to an expression for the demand for money when households face no adjustment costs. It is natural to interpret this money demand relation as a long-run equilibrium relation. Dynamic adjustment towards this long-run equilibrium can be motivated in several ways. The simplest way is to assume that it can be represented by a vector error correction model (VECM)

$$
\Delta x_{t}=\sum_{i=1}^{k-1} \Gamma_{i} \Delta x_{t-i}+\alpha \beta^{\prime} x_{t-1}+\Upsilon D_{t}+\epsilon_{t}, \quad \epsilon_{t} \sim N I D(0, \Omega),
$$

where $x_{t}=\left[(m-p)_{t}, y_{t}, R_{t}\right]^{\prime}$ and $D_{t}$ is a $s \times 1$ vector of deterministic variables, such as constant and dummy variables. $\alpha$ is the factor loading matrix and $\beta^{\prime}=(1,-\eta, \theta)$ is the cointegrating vector from the long-run analysis above.

\footnotetext{
${ }^{5}$ The assumption of constant variances is in fact unnecessary strict. Since the variances are stationary, the stochastic trends in $(m-p)_{t}, c_{t}$ and $R_{t}$ will dominate any variation in the variances in the cointegrating analysis.
} 
One way of interpreting the VECM is simply as a parsimonious method of representing lag responses. It can, however, also be derived explicitly from a cost minimization problem, where households minimize the expected present value of a cost function where they are penalized if actual money holdings deviate from the long-run target and for adjusting their actual money holdings (cf. Cuthbertson and Taylor (1987) and Cuthbertson and Taylor (1990))

$$
E_{t}\left(\sum_{i=0}^{\infty} \delta^{i}\left[\phi\left\{(m-p)_{t+i}-\left(m^{*}-p\right)_{t+i}\right\}^{2}+\left\{\Delta(m-p)_{t+i}\right\}^{2}\right]\right),
$$

where $\left(m^{*}-p\right)_{t}$ denotes the desired real money balances when households face no adjustment costs, as derived from the previous section. ${ }^{6}$

The solution to this minimization problem can be written as a forward-looking ECM for real money balances (see e.g. Sargent (1979))

$$
\Delta(m-p)_{t}=(1-\lambda) \sum_{i=0}^{\infty}(\lambda \delta)^{i} \beta_{z}^{\prime} E_{t} \Delta z_{t+i}-(1-\lambda) \beta^{\prime} x_{t-1},
$$

where the data vector has been partitioned as $x_{t}=\left[(m-p)_{t}, z_{t}\right]^{\prime}$, where $z_{t}=\left(y_{t}, R_{t}\right)^{\prime}$, and the cointegrating vector as $\beta=\left(1:-\beta_{z}\right)$. $\lambda$ is the stable root of the quadratic equation $\delta \ell^{2}-(1+\delta+\phi) \ell+1=0$ from the Euler equation of the optimization problem in (2.13).

\section{THE DATA}

This paper analyses the demand for money in Iceland, using annual data for the period between 1962 and 1995. As a measure of money, broad money (M3) is used. As a scale variable, gross domestic output (GDP) is chosen and the implicit GDP price deflator as a measure of prices. Both variables are measured as annual averages and output is measured at constant, 1990 prices. The final variable in the model measures the opportunity cost of money. Since interest rates in Iceland were not market determined for the main part of the period analysed here and alternative financial assets were generally not available to individual investors, it is not clear how the opportunity cost of money holdings should be defined.

Interest rates became partially market determined in 1984 when banks were allowed to determine their own rates. A market for short-term bills did not, however, emerge until 1987 when trading with treasury bills initiated. Prior to 1987, individual investors had few available asset choices other than money or real assets, such as real estate or consumer durables. The rate of inflation is therefore used as a proxy for the rate of return on these alternative real assets. After 1987, however, new financial instruments gradually became available and individual investors were able to invest their wealth in more liquid assets such as treasury and banking bills. As these new assets were introduced, individual asset holders had to learn about their

\footnotetext{
${ }^{6}$ The cost minimization problem is specified in terms of real money balances, as in e.g. Cuthbertson and Taylor (1990), since the growth rate of real money balances is found to be stationary whereas the growth rate of nominal money balances is found to be non-stationary. This has, however, the unappealing implication that adjustments of nominal money holdings are costless if prices adjust by the same magnitude, see Goodfriend (1990). Engsted and Haldrup (1999) avoid this problem by analysing the $I(2)$ system and derive testable restrictions on the exact forward-looking model (2.14).
} 

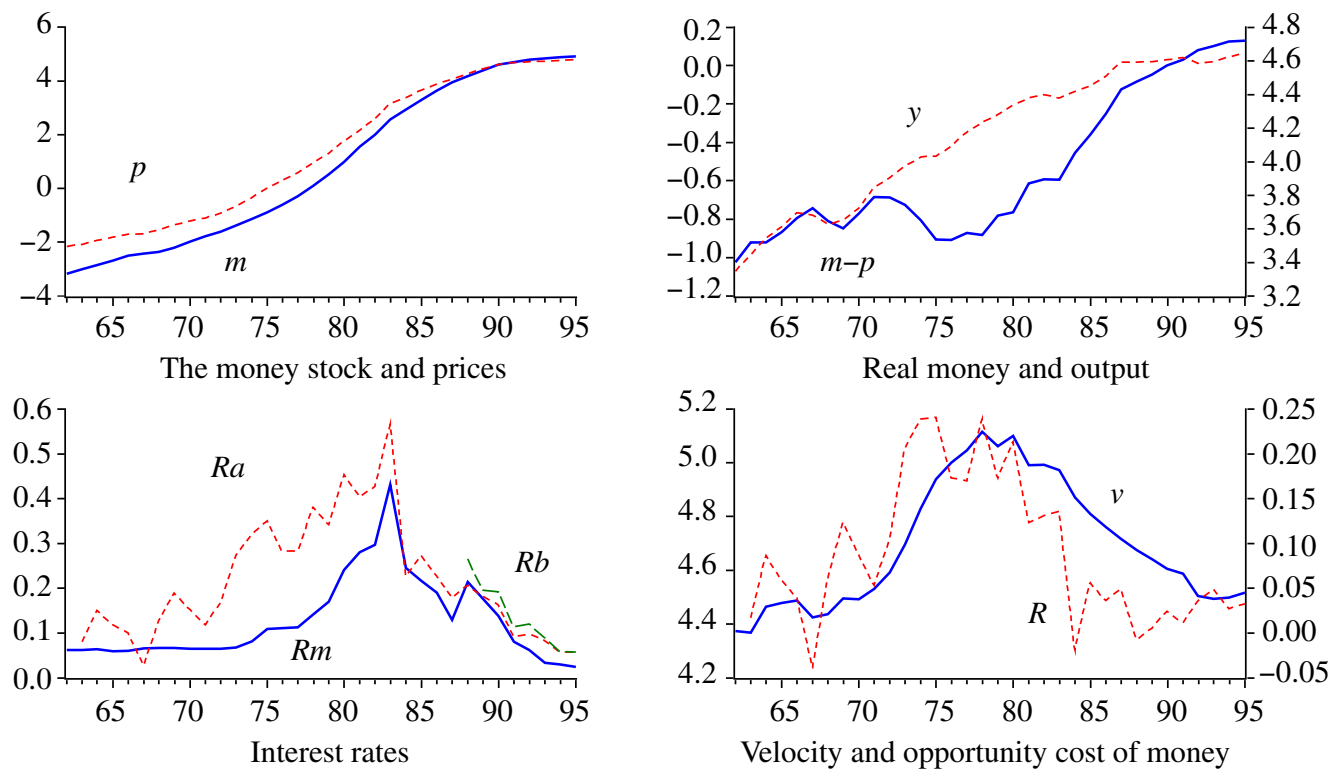

Figure 1. The data.

existence and characteristics. Therefore it is assumed that the introduction of liquid, shortterm assets in 1987 only affected investment behaviour gradually. Hence, the rate of return on alternative assets is calculated using a 'learning-adjusted' rate

$$
R_{a t}=\Delta p_{t}+w_{t}\left(R_{b t}-\Delta p_{t}\right),
$$

where $\Delta p_{t}$ is inflation, $R_{b t}$ is the interest rate on treasury bills (used to proxy liquid, short-term assets) and $0 \leq w_{t} \leq 1$ is the weight at time $t$, reflecting knowledge of the characteristics on the newly introduced asset (cf. Baba et al. (1991) and Hendry and Ericsson (1991) for similar ideas). The learning curve, $w_{t}$, is given by a logistic function with the rate of learning chosen such that $w_{t}$ is about a half in 1991 and unity in $1995 .^{7}$

The opportunity cost measure used in this paper is given by the spread between this learning-adjusted alternative rate and the own rate of money, $R_{m t}$ (calculated as a weighted average deposit rate on M3 assets)

$$
R_{t}=R_{a t}-R_{m t}
$$

Figure 1 plots the data. Two things should be noted. First, a positive long-run relation between velocity of money, $v_{t}=y_{t}-(m-p)_{t}$, and the opportunity cost of money, $R_{t}$, seems evident. Both velocity and the opportunity cost rise considerably until 1979, when widespread financial indexation was introduced. After that, both start declining.

Second, it seems obvious that money and prices are not stationary. The smoothness of $m_{t}$ and $p_{t}$ would further suggest that these processes are close to being $I(2)$, but the more

\footnotetext{
${ }^{7}$ The main results remain largely unchanged when $w_{t}=(0,1)$, i.e. when $R_{a t}=\Delta p_{t}$ for the whole period or when $R_{a t}=R_{b t}$ immediately after 1987 . Other values of initial knowledge and the speed of learning gave similar results.
} 
Table 1. Cointegration tests.

\begin{tabular}{|c|c|c|c|c|}
\hline$H_{0}$ hypothesis & Eigenvalues & $\lambda_{\text {trace }}$ & $\begin{array}{c}90 \% \text { critical } \\
\text { values }\end{array}$ & $\begin{array}{c}95 \% \text { critical } \\
\text { values }\end{array}$ \\
\hline$r=0$ & 0.625 & 57.33 & 46.42 & 49.68 \\
\hline$r \leq 1$ & 0.532 & 26.94 & 28.36 & 31.19 \\
\hline$r \leq 2$ & 0.103 & 3.37 & 13.48 & 15.35 \\
\hline \multicolumn{5}{|c|}{ Standardized eigenvectors $\beta^{\prime}$} \\
\hline$(m-p)_{t}$ & $y_{t}$ & $R_{t}$ & $\sum_{s=1}^{t} d_{84 s}$ & $t$ \\
\hline 1 & -1.184 & 5.226 & 0.298 & -0.0006 \\
\hline 1.040 & 1 & 0.889 & -0.232 & -0.064 \\
\hline 0.065 & 0.528 & 1 & 0.270 & -0.027 \\
\hline \multicolumn{3}{|c|}{ LR-test for excluding $\left(\sum_{s=1}^{t} d_{84 s}, t\right)$ from $\beta$} & $\chi^{2}(2)=3.27$ & $(p=0.19)$ \\
\hline
\end{tabular}

erratic nature of $(m-p)_{t}$ implies that $(m-p)_{t}$ is $I(1)$. This indicates that money and prices cointegrate, with the cointegrating vector $(1,-1)$. This again implies a long-run price elasticity of unity, which will be imposed throughout the paper. The model is therefore estimated for real rather than nominal money, as suggested by the theoretical model in the previous section. Output, the rate of returns $\left(R_{a t}\right.$ and $\left.R_{m t}\right)$ and velocity all seem to be $I(1)$. The opportunity cost measure, $R_{t}$, also seems to be $I(1)$, even though it is a net rate (or a real rate) which might be expected to be stationary. From the figure, however, it is evident that it is more appropriate to treat this series as difference stationary rather than level stationary. Therefore it seems appropriate to treat $(m-p)_{t}, y_{t}$ and $R_{t}$ as $I(1)$ series, implying that their growth rates are stationary (this is formally tested within the cointegration analysis below).

\section{ESTIMATION RESULTS}

\subsection{Cointegration analysis}

Before the system (2.12) is estimated with the full information maximum likelihood (FIML) method of Johansen (1988), the nature of the deterministic variables, and how they enter the model, and the model's lag structure need to be determined. The intercept cannot be restricted a priori to lie in the cointegration space as a deterministic trend in output cannot be ruled out, cf. Figure 1. There should, however, be no trend in the interest rate. The intercept is therefore included unrestrictedly. The model includes one impulse dummy variable for the year $1984, d_{84 t}$, corresponding to a structural change in the Icelandic financial system, due to the liberalization of interest rate determination. ${ }^{8}$ It would have been preferred to model this

\footnotetext{
${ }^{8}$ The dummy variable takes the value unity in 1984 and zero otherwise. Due to the definition of $R_{t}, d_{84 t}$ could also be interpreted as a structural break in the price process, when inflation fell from $60 \%$ in 1983 to $20 \%$ in 1984 . This structural break is fully explained by changes in wages and import prices, see Pétursson (1998).
} 
Table 2. Residual analysis.

\begin{tabular}{lccclll}
\hline & $\Delta(m-p)_{t}$ & $\Delta y_{t}$ & $\Delta R_{t}$ & & \multicolumn{2}{c}{ System } \\
\cline { 1 - 2 }$(\%)$ & 5.66 & 3.62 & 4.95 & & $F_{\text {ar } 1-2}(18,42)$ & 0.96 \\
$F_{\text {ar1-2 }}(2,21)$ & 0.58 & 0.22 & 0.64 & & $F_{\text {het }}(72,33)$ & 0.91 \\
$F_{\text {arch } 1(1,21)}$ & 0.52 & 0.43 & 0.35 & & $\chi_{n}^{2}(6)$ & 0.19 \\
$F_{\text {het }}(12,10)$ & 0.17 & 0.92 & 0.68 & & & \\
$\chi_{n}^{2}(2)$ & 0.84 & 0.44 & 0.50 & & \\
\hline
\end{tabular}

Note: $\widehat{\sigma}$ denotes the standard error of each equation. $F_{\text {ar } 1-2}$ denotes an $F$-test for no serial correlation, against a second-order autocorrelation. $F_{\text {arch } 1}$ denotes the Engle (1982) test for no autoregressive conditional heteroscedasticity, against a first-order ARCH effect. $F_{h e t}$ denotes the White (1980) test for no heteroscedasticity. $\chi_{n}^{2}$ denotes the Doornik and Hansen (1993) normality test. The table reports $p$-values of corresponding tests.

structural break explicitly, but as the dummy variable is not found to be significant in the money demand equation, which is of primary interest, this is not pursued here. The dummy variable is also included unrestrictedly. For the specification of the lag structure, $k=2$ was chosen. A likelihood ratio (LR) test for lag 2 against lag 3 gave a test statistic of $F(9,41)=0.96$ ( $p=0.49$ ), using Rao's $F$-approximations of the LR-test (see Doornik and Hendry (1995)).

Table 1 reports the results of the reduced rank regressions and the Johansen (1988) tests for the number of cointegrating vectors. Since the constant and the impulse dummy variable, $d_{84 t}$, enter the model unrestrictedly outside the cointegration vectors, a nuisance parameter problem arises. Rahbek and Mosconi (1999) suggest that this problem can be solved by adding the cumulated constant and dummy variable (i.e. a trend and step dummy $\sum_{s=1}^{t} d_{84 s}$ ) to the cointegrating system when testing the reduced rank properties of the data. After the rank has been determined, one may test whether these additional variables can be excluded from the cointegrating relations with a standard LR-test. However, because of the cumulated dummy variable in the cointegration analysis, the asymptotic distribution of the rank test is different from the distribution tabulated for standard models. Thus, the quantiles of the asymptotic distribution are simulated using the DisCo program of Johansen and Nielsen (1993).

The results from Table 1 suggest one cointegrating vector in this data set, both at the $90 \%$ and $95 \%$ critical levels. $^{9}$ The LR-test for excluding the trend and the cumulative dummy variable from the cointegrating vector does not reject. In the following analysis these redundant variables are therefore excluded.

Table 2 reports mis-specification tests for the cointegrated VAR. As can be seen, these tests suggest no serious specification problems: the tests do not reject that the residuals of each equation are normally distributed white noise processes. The same applies for the system. The system furthermore showed no evidence of non-constancy, using recursive techniques. ${ }^{10}$

\footnotetext{
${ }^{9}$ As the critical values are more suited to larger data sets than used here, the formal test statistics must be interpreted with caution. The small sample corrections suggested by Reimers (1992) were not used since the results in Kostial (1994) indicate a tendency for the critical values to underestimate the dimension of the cointegrating space even when unadjusted.

${ }^{10}$ It should be kept in mind that relatively few observations are used in the recursive estimates. These results, and others not reported here, are available upon request.
} 
Table 3. Testing restrictions on $\alpha$ and $\beta$.

\begin{tabular}{lcc}
\hline $\begin{array}{l}\text { Testing restrictions on } \beta \\
\text { Restrictions on } \eta=\frac{\omega}{\psi}\end{array}$ & Test statistic & $p$-value \\
\hline$H_{0}: \eta=1$ & $\chi^{2}(1)=2.95$ & 0.09 \\
$H_{0}: \eta=1 / 2$ & $\chi^{2}(1)=16.57$ & 0.00 \\
$H_{0}: \eta=1 / 3$ & $\chi^{2}(1)=19.66$ & 0.00 \\
Testing restrictions on $\alpha$ & & \\
Weak exogeneity restrictions & Test statistic & $p$-value \\
\hline$H_{0}: \alpha_{y}=0$ & $\chi^{2}(1)=2.10$ & 0.15 \\
$H_{0}: \alpha_{R}=0$ & $\chi^{2}(1)=1.62$ & 0.20 \\
$H_{0}: \alpha_{y}=\alpha_{R}=0$ & $\chi^{2}(2)=3.79$ & 0.15 \\
Joint test: & & \\
$H_{0}: \eta=1, \alpha_{y}=\alpha_{R}=0$ & $\chi^{2}(3)=6.84$ & $p=0.08$ \\
Testing stationarity restrictions & & \\
Stationarity restrictions & Test statistic & $p$-value \\
\hline$H_{0}:(m-p)_{t} \sim I(0)$ & $\chi^{2}(2)=25.14$ & 0.00 \\
$H_{0}: y_{t} \sim I(0)$ & $\chi^{2}(2)=24.38$ & 0.00 \\
$H_{0}: R_{t} \sim I(0)$ & $\chi^{2}(2)=22.16$ & 0.00 \\
$H_{0}: v_{t} \sim I(0)$ & $\chi^{2}(2)=25.61$ & 0.00 \\
\hline
\end{tabular}

Note: The LR-tests on the cointegrating space and the factor loadings are derived in Johansen and Juselius (1990).

\subsection{The restricted cointegration vector}

As it stands, the theoretical money demand model in (2.11) imposes no over-identifying restrictions on the cointegrating space. However, standard models of money demand suggest various values for the long-run income elasticity, $\eta$. Therefore it would be interesting to test these restrictions. Table 3 reports the results. As seen in the first part of Table 3, income elasticity of unity is not rejected at the $95 \%$ critical level, whereas values of $\frac{1}{2}$ and $\frac{1}{3}$ are strongly rejected, therefore rejecting the transaction model of Baumol (1952) and Tobin (1956) and the precautionary model of Miller and Orr (1966) in this data set.

The second part in Table 3 reports tests of weak exogeneity of the forcing variables, $y_{t}$ and $R_{t}$, for the long-run parameters. The LR-tests indicate that $y_{t}$ and $R_{t}$ are weakly exogenous for the long-run parameters in the money demand equation, which is a necessary condition for valid conditioning on these variables (see Engle et al. (1983)). ${ }^{11}$ When the restrictions on $\alpha$ and $\beta$ are tested jointly, the LR-test gives $\chi^{2}(3)=6.8(p=0.08)$. The final part of

${ }^{11}$ When a similar test is conducted for $(m-p)_{t}$ the LR-test gives $\chi^{2}(1)=1.2(p=0.2)$, thus not rejecting weak exogeneity of real money balances with respect to the cointegrating vector. This, with weak exogeneity of the forcing variables, would suggest no cointegration among the variables contradicting the results from the cointegrating analysis. Based on the results from the cointegration analysis, recursive estimates of the eigenvalues of the long-run matrix, the apparent relation between velocity and the opportunity cost in Figure 1, and the strong significance of the cointegrating relation in the conditional analysis below, the maintained assumption will be that there is a cointegrating relation in the system. It should also be noted that when $\alpha_{y}$ and $\alpha_{R}$ are set to zero (as suggested by the results in Table 3), the cointegrating vector becomes strongly significant in the real money equation, with a factor loading equal to -0.24 and a standard error equal to 0.04 . 
Table 3 reports tests for stationarity of individual series and velocity. The LR-test strongly rejects stationarity in all cases.

The cointegrating vector used in this study therefore imposes a unit long-run income elasticity, thus implying equal values of the risk aversion parameters, and weak exogeneity of $y_{t}$ and $R_{t}$ with respect to the long-run parameters. The resulting long-run relation implies a positive long-run relation between velocity and the opportunity cost of money (standard error in parentheses)

$$
\left(m^{*}-p\right)_{t}=y_{t}-\underset{(0.41)}{4.030} R_{t}+\text { const. }
$$

The results suggest homothetic preferences, indicating that households are equally averse to variations in consumption and real money balances. The implied value of $\widehat{\omega}=\widehat{\psi}$ is 0.25 with a standard error of 0.021 (calculated using Cramér's rule). These estimates are in the lower region of cross-country estimates from consumption-based asset-pricing models. They typically find estimates of the risk aversion parameters lying in the region $0.5-4$ for different countries. Furthermore, when the set of assets is augmented with stocks, the risk aversion parameter is typically higher, lying in the region 2-6, see Roy (1995). Allowing for habit persistence in utility widens the estimation region further to 0.35-12, see Braun et al. (1993).

\subsection{A conditional ECM for real money balances}

Since the forcing variables were found to be weakly exogenous for the long-run parameters of the money demand equation, efficient estimates of parameters of interest can be obtained from analysing the conditional density of real money balances, given $y_{t}$ and $R_{t}$ and the past history of the process alone. This amounts to estimating a single-equation money demand relation. The final model, with the long-run money relation from (4.1) used, is given by (the mis-specification tests report $p$-values)

$$
\widehat{\Delta(m-p)}=\underset{(0.12)}{0.769} \Delta y_{t}-\underset{(0.09)}{0.755 \Delta} \Delta R_{t}+\underset{(0.02)}{0.174}(v-4.030 R)_{t-1}-\underset{(0.09)}{0.752}
$$

OLS, $1964-1995(T=32), \bar{R}^{2}=0.80, \widehat{\sigma}_{\epsilon}=2.74 \%, F_{\text {enc }}(5,22)=0.56, F_{\text {ar } 1-2}(2,26)=$ $0.90, F_{\text {arch } 1}(1,26)=0.42, \chi_{n}^{2}(2)=0.06, F_{\text {het }}(6,21)=0.49, F_{f n}(9,18)=0.60, F_{\text {for }}(5,23)=$ $0.28, F_{\text {chow } 79}(12,12)=0.87$.

The numbers in parentheses are White's (1980) heteroscedasticity-adjusted standard errors. $\bar{R}^{2}$ is the degrees of freedom-adjusted coefficient of determination, $F_{\text {enc }}$-tests for parsimonious encompassing, testing the validity of the simplifying restrictions on an unrestricted distributed lag model with two lags of each variable. The ECM imposes five over-identifying restrictions on the distributed lag model which are easily accepted. $F_{f n}$ is the White (1980) test for no specification error. $F_{\text {for }}$ is the Chow test for no forecast instability for the last 5 years. $F_{\text {chow } 79}$ is a Chow test for a structural break in 1979, the year that widespread financial indexation was introduced in Iceland. Other tests have previously been explained.

The mis-specification tests all imply that the hypothesis of normally distributed, homoscedastic innovation errors is not rejected. There is no evidence of instability in- or outside the sample. Finally, there is no evidence of functional mis-specification. ${ }^{12}$ The model explains $80 \%$ of the

\footnotetext{
${ }^{12}$ The impulse dummy, $d_{84 t}$, is found insignificant, with an $F$-statistic of $F(1,28)=1.2(p=0.29)$.
} 
growth in real money balances with a standard error of $2.7 \%$. All parameters are well determined and with correct signs, allowing (4.2) to be interpreted as a money demand equation. Finally, recursive estimates (not reported here) indicate no instability of the conditional money demand equation.

\subsection{The forward-looking specification}

This final section proposes a forward-looking, rational expectations interpretation of the shortrun dynamics of the money demand equation using the cost minimization problem in (2.13). To obtain a closed form solution to (2.14) some assumptions must be made concerning the data-generating process for the forcing variables $\Delta z_{t}$. The obvious choice is the marginal VECM model for $\Delta z_{t}$ in (2.12) with $k=2$ (abstracting from deterministic terms to simplify the notation)

$$
\Delta z_{t}=\Gamma_{z 1} \Delta x_{t-1}+\alpha_{z} \beta^{\prime} x_{t-1}+\epsilon_{z t},
$$

where $\Gamma_{1}=\left(\Gamma_{m 1}: \Gamma_{z 1}\right), \alpha=\left(\alpha_{m}: \alpha_{z}\right)$ and $\epsilon_{t}=\left(\epsilon_{m t}: \epsilon_{z t}\right)$ have been partitioned accordingly. The previous analysis indicated that the forcing variables are weakly exogenous for the longrun parameters, i.e. $\alpha_{z}=0$. Furthermore, $\Delta(m-p)_{t}$ is not found to Granger (1969) cause $\Delta y_{t}$ or $\Delta R_{t}, \chi^{2}(2)=0.39(p=0.82)$. Thus, $\Delta y_{t}$ and $\Delta R_{t}$ are strongly exogenous in the sense of Engle et al. (1983) with respect to the parameters of interest in the money demand equation.

The data-generating process for $\Delta z_{t}$ can therefore be approximated as

$$
\Delta z_{t}=\Gamma_{z z 1} \Delta z_{t-1}+\epsilon_{z t}
$$

where $\Gamma_{z 1}=\left(\Gamma_{z m 1}: \Gamma_{z z 1}\right)$, and $\Gamma_{z m 1}=0$ as $\Delta(m-p)_{t}$ does not Granger cause $\Delta y_{t}$ or $\Delta R_{t}$.

From (4.4) it is simple to generate future expectations of $\Delta z_{t}$ using the law of iterated expectations

$$
E_{t} \Delta z_{t+i}=\Gamma_{z z 1}^{i} \Delta z_{t} .
$$

Inserting this optimal projection into (2.14) gives

$$
\Delta(m-p)_{t}=\mathrm{const}+(1-\lambda)\left(I-\lambda \delta \Gamma_{z z 1}\right)^{-1} \beta_{z}^{\prime} \Delta z_{t}-(1-\lambda) \beta^{\prime} x_{t-1}+e_{t} .
$$

In (4.6) an error term, $e_{t}$, has been added, reflecting the fact that the optimization problem above is only a crude approximation of actual household behaviour. It is common to interpret this error term as the difference between the expected future paths of the forcing variables conditional on the information set available to households and the information set available to the econometrician, respectively. This interpretation does not hold here since if households have such superior information, then according to $(2.14) \Delta(m-p)_{t}+(1-\lambda) \beta^{\prime} x_{t-1}$ should be the optimal predictor of future $\Delta z_{t}$, implying that $\Delta(m-p)_{t}$ should Granger cause $\Delta z_{t}$ (see Campbell and Shiller (1987)). However, as noted above, this is not the case here, i.e. households only seem to use information contained in current and lagged $\Delta z_{t}$. Thus, the error term could instead reflect factors such as unforeseen difficulties in implementing plans (Cuthbertson and Taylor (1987)), measurement errors and approximation errors when using a quadratic loss function (e.g. due to an important buffer stock element in money holdings, cf. Cuthbertson and Taylor (1990)). 
Table 4. GMM estimation of the forward-looking system.

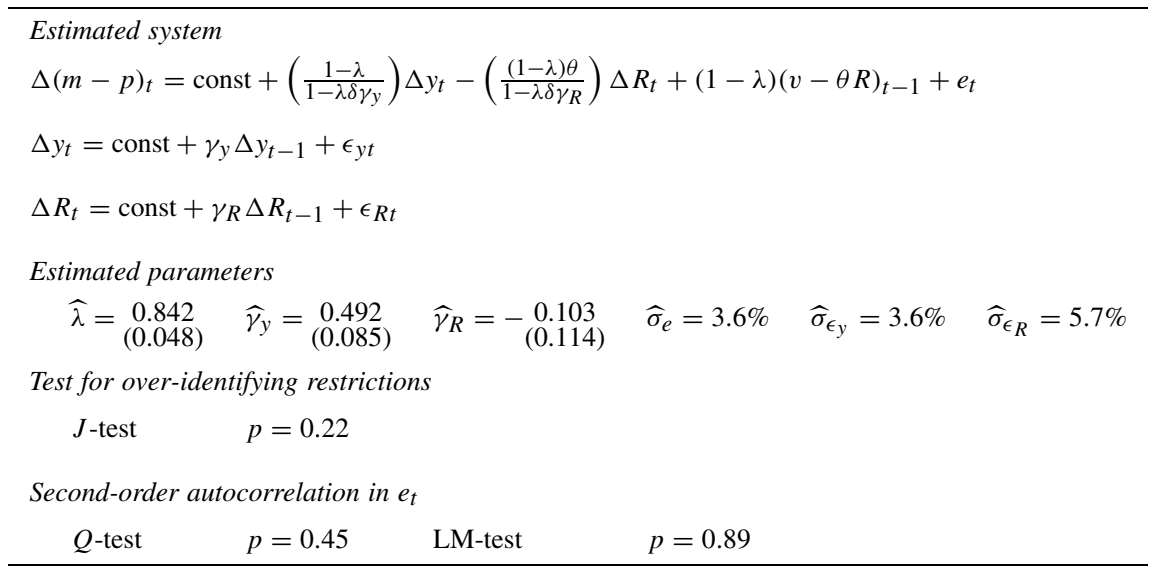

Note: Instruments used are $\Delta y_{t-1}, \Delta R_{t-1},(v-\theta R)_{t-1}$ and $d_{84 t}$.

The forward-looking money demand equation is estimated simultaneously with the expectations generating process for $\Delta z_{t}$ in (4.4) using Hansen's (1982) general method of moments (GMM). As the cointegrating vector $\beta$ is estimated super-consistently, it can be treated as fixed when estimating the money demand equation, just as when estimating the conditional ECM above. Furthermore, as is standard in the rational expectations literature, the discount factor $\delta$ is taken as given. The value of $\delta$ is chosen as 0.96 , which corresponds approximately to a $4 \%$ annual rate of time preferences. Thus, only $\lambda$ and $\Gamma_{z z 1}$ are estimated. Finally, analysis of the marginal VECM in (4.4) above indicates that the marginal equations for $\Delta y_{t}$ and $\Delta R_{t}$ can be approximated by univariate AR-equations, $\chi^{2}(2)=2.38(p=0.30)$. Therefore the off-diagonal elements of $\Gamma_{z z 1}$ are set to zero. The reduction from the cointegrated VAR in (4.3) to the univariate AR-equations is easily accepted, $\chi^{2}(6)=5.94(p=0.43)$.

The estimates of the forward-looking system are reported in Table 4 with heteroscedasticityand autocorrelation-consistent standard errors in parentheses.

The restricted system estimate of the forward-looking model implies an error correction coefficient of $(1-\widehat{\lambda})=0.158$, which is almost identical to the estimate from the unrestricted, conditional ECM from above. ${ }^{13}$ Hansen's (1982) $J$-test for over-identifying restrictions does not reject and autocorrelation tests show no evidence of any persistence in $e_{t}$. The forwardlooking, rational expectations interpretation of the money demand equation is therefore not rejected and the restricted estimates of the dynamic adjustment coefficients are very similar to the estimates from the unrestricted ECM. Furthermore, deviations from the exact rational expectations model (2.14), captured in $e_{t}$, seem to be only transitory and economically unimportant.

\footnotetext{
${ }^{13}$ The implied coefficients on $\Delta y_{t}$ and $\Delta R_{t}$ in the forward-looking model are 0.26 and -0.59 , respectively, which are quite close to the unrestricted estimates in (4.2), although the short-run income elasticity is somewhat smaller.
} 


\section{CONCLUSIONS}

This paper analyses the demand for broad money in Iceland in the period between 1962 and 1995. A model of a representative household with money-in-the-utility-function preferences is used to derive the steady-state solution for money demand used in the empirical analysis.

A multivariate error correction model for real money balances, real output and a measure of the opportunity cost of money is then estimated. From the cointegration analysis a single cointegrating relation is found. Testing over-identifying restrictions on the cointegrating space suggests a unit long-run income elasticity which implies a long-run relation between velocity and the opportunity cost of money holdings. This also implies homothetic preferences and that households are equally averse to variations in real consumption and real money balances. The estimated value of the risk aversion parameters is $\frac{1}{4}$ which is in the lower region of estimates found in international studies.

The results from the cointegration analysis imply that output and the opportunity cost are weakly exogenous for the long-run parameters. A conditional model, amounting to a single-equation money demand equation, can therefore be estimated. The money demand equation shows remarkable stability, in spite of large fluctuations in the conditional variables and substantial changes in the institutional framework in the domestic financial market, such as the introduction of financial indexation in 1979, interest rate liberalization in 1984 and the introduction of a secondary market for financial instruments in 1987. The model explains a large proportion of changes in the growth rate of real balances, e.g. the large decline of real balances between 1972 and 1976, the large fall in velocity from 1981 to 1984, and the large increase in real balances from 1984 to 1987.

Finally, a forward-looking interpretation of the error correction mechanism is analysed. The over-identifying cross-equation restrictions implied by rational expectations are not rejected. The money demand equation could therefore be interpreted as a forward-looking error correction model.

At least three policy implications follow from the analysis. First, money seems to be endogenously determined by the private sector, whereas the monetary policy authority targets the interest rate. Secondly, money demand appears stable despite substantial financial innovation. However, the effects of financial innovation on the opportunity cost of money have to be taken into account to obtain this stable demand relation. Finally, a forward-looking interpretation of the short-run adjustment dynamics is not rejected, implying that households determine their desired money holdings in a forward-looking fashion.

\section{ACKNOWLEDGEMENTS}

This paper is based on Chapter 3 of my PhD thesis at the University of Aarhus, Denmark. I would like to thank my supervisors Torben M. Andersen and Svend Hylleberg and the members of my thesis committee Niels Haldrup, Stephen Hall and Henrik Jensen for their help. Furthermore, I am grateful for comments and suggestions from two anonymous referees and two editors of this journal, H. Peter Boswijk and Neil Shephard. Finally, I would like to thank Fridrik M. Baldursson, Gudmundur Gudmundsson, Már Gudmundsson, Tómas Hansson, Helgi Tómasson and seminar participants at the CNLME workshop in Kokkedal Slot, Denmark for helpful comments on earlier drafts. The usual disclaimer applies. The views expressed in 
this paper are solely those of the author and should not be interpreted as necessarily reflecting those of the Central Bank of Iceland.

\section{REFERENCES}

Baba, Y., D. F. Hendry and R. M. Starr (1991). The demand for M1 in the U.S.A., 1960-1988. Review of Economic Studies 59, 25-61.

Baumol, W. J. (1952). The transaction demand for cash: An inventory theoretic approach. Quarterly Journal of Economics 66, 545-56.

Braun, P. A., G. M. Constantinides and W. E. Ferson (1993). Time non-separability in aggregate consumption: International evidence. European Economic Review 37, 897-920.

Campbell, J. Y. and R. J. Shiller (1987). Cointegration and tests of present value models. Journal of Political Economy 95, 1062-88.

Cornelius, P. K. (1990). Monetary indexation and revenues from money creation: The case of Iceland. IMF Working Papers, WP/90/20.

Cuthbertson, K. and M. P. Taylor (1987). The demand for money: A dynamic rational expectations model. Economic Journal 97, 65-76.

Cuthbertson, K. and M. P. Taylor (1990). Money demand, expectations, and the forward-looking model. Journal of Policy Modeling 12, 289-315.

Doornik, J. A. and H. Hansen (1993). A practical test for multivariate normality, unpublished manuscript. Nuffield College: Oxford.

Doornik, J. A. and D. F. Hendry (1995). Pc-Fiml 8.0. Interactive Econometric Modelling of Dynamic Systems. London: Chapman and Hall.

Eggertsson, T. (1982). Inflation expectations and the demand for money in Iceland. Scandinavian Journal of Economics 84, 1-12.

Engle, R. F. (1982). Autoregressive conditional heteroscedasticity, with estimates of the variance of United Kingdom inflation. Econometrica 50, 987-1007.

Engle, R. F., D. F. Hendry and J.-F. Richard (1983). Exogeneity. Econometrica 51, 277-307.

Engsted, T. and N. Haldrup (1999). Estimating the LQAC model with I(2) variables. Journal of Applied Econometrics 14, 155-70.

Feenstra, R. (1986). Functional equivalence between liquidity costs and the utility of money. Journal of Monetary Economics 17, 271-91.

Friedman, M. (1956). Studies in the Quantity Theory of Money. Chicago: University of Chicago Press.

Goldfeld, S. M. and D. E. Sichel (1990). The demand for money. In Friedman, B. and Hahn, F. (eds), Handbook of Monetary Economics, vol. I, pp. 299-356. Amsterdam: North-Holland.

Goodfriend, M. (1990). Comment. Journal of Policy Modeling 12, 317-22.

Granger, C. W. J. (1969). Investigating causal relations by econometric models and cross-spectral methods. Econometrica 37, 24-36.

Gudmundsson, G. (1986). Peningamagn og vextir [Money and interest rates]. Fjármálatídindi 33, 95-104.

Hansen, L. P. (1982). Large sample properties of generalized methods of moments estimators. Econometrica 50, 1029-54.

Hendry, D. F. and N. E. Ericsson (1991). Modeling the demand for narrow money in the United Kingdom and the United States. European Economic Review 35, 833-81.

Hoffman, D. L., H. Raasche and M. A. Tieslau (1995). The stability of long-run money demand in five industrial countries. Journal of Monetary Economics 35, 319-39.

Johansen, S. (1988). Statistical analysis of cointegration vectors. Journal of Economic Dynamics and Control 12, 231-54.

Johansen, S. and K. Juselius (1990). Maximum likelihood estimation and inference on cointegrationWith applications to the demand for money. Oxford Bulletin of Economics and Statistics 52, 169-210.

(C) Royal Economic Society 2000 
Johansen, S. and B. Nielsen (1993). Manual for the simulation program DisCo, unpublished manuscript. Institute of Mathematical Statistics, University of Copenhagen.

Kostial, K. (1994). The role of the signal-noise matrix in the estimation of cointegrated systems, European University Institute, Economics Department Discussion Paper no. EC94/27.

Lucas, R. E. Jr. (1988). Money demand in the United States: A quantitative review. Carnegie-Rochester Series on Public Policy 29, 137-68.

Miller, M. H. and D. Orr (1966). A model of the demand for money by firms. Quarterly Journal of Economics 80, 413-35.

Pesaran, M. H. (1997). The role of economic theory in modelling the long run. Economic Journal 107, 178-91.

Pétursson, T. G. (1998). Price determination and rational expectations. International Journal of Finance and Economics 3, 157-67.

Poterba, J. M. and J. Rotemberg (1987). Money in the utility function: An empirical implementation. In Barnett, W. A. and Singleton, K. J. (eds.), New Approaches to Monetary Economics, pp. 219-46. Cambridge: Cambridge University Press.

Rahbek, A. and R. Mosconi (1999). Cointegration rank inference with stationary regressors in VAR models. Econometrics Journal 2, 76-91.

Reimers, H. E. (1992). Comparisons of tests for multivariate cointegration. Statistical Papers 33, 335-59.

Ripatti, A. (1996). Stability of the demand for M1 and harmonized M3 in Finland, Bank of Finland Discussion Papers, no. 18/96.

Roy, A. (1995). Multicountry comparison of the consumption based capital asset pricing model: Germany, Japan and USA, LSE Financial Market Group, Discussion Paper 209.

Sargent, T. J. (1979). Macroeconomic Theory. New York: Academic Press.

Tobin, J. (1956). The interest-elasticity of transaction demand for cash. Review of Economics and Statistics $38,241-7$.

White, H. (1980). A heteroscedastic-consistent covariance matrix estimator and a direct test of heteroscedasticity. Econometrica 48, 817-38. 